\title{
Heuristics and pattern recognition in complex geo-referenced systems
}

\author{
Gilbert Ahamer, Adrijana Car, Robert Marschallinger, \\ Gudrun Wallentin and Fritz Zobl \\ Institute for Geographic Information Science at the Austrian Academy of Sciences \\ ÖAW/GIScience, Schillerstraße 30, A-5020 Salzburg, Austria
}

\begin{abstract}
We propose different methods to represent "time" in geographic and other perceptions of reality. One appropriate method is to show effects of the procedures which take "place" along the continuum of "time". Similarly, perspectives on reality can be "mapped" - such is the core of geography.

This presents a special opportunity for IT to develop tools for various disciplines which are then interchangeable. IT allows views on new worlds. These worlds arise by applying new perspectives to known reality. IT helps to organise the complexity of the resulting views. IT creates images of reality. IT is able to move from "Geographic Information Science" to "Interperspective Information Science".

Additionally, it is able to host negotiation processes that generate new spaces of understanding created by consensus building.

The above two tasks for IT creatively contribute to building a "network society".
\end{abstract}

Key Words: Geographic Information Science (GIS), mapping, time, space, perception, consensus building, social space.

\section{Let's start to think}

1.1 Our world is the entirety of perceptions. (Our world is not the entirety of facts.)
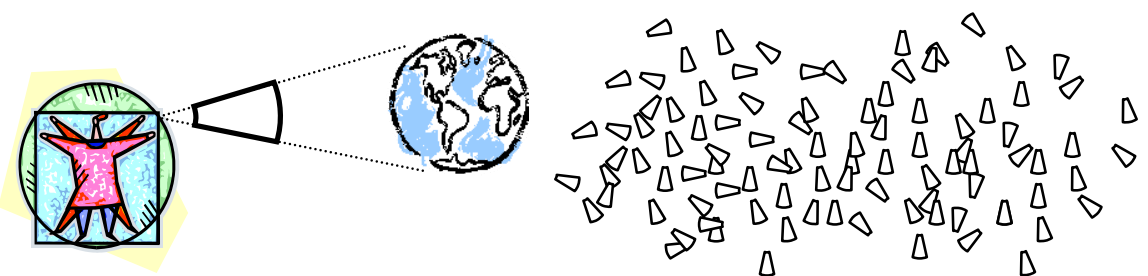

Fig. 1. At left: The human being perceives the world. At right: The "primordial soup" of living, before the advent of (social) organisms: uncoordinated perspectives, uncoordinated world views. 
Hence, every individual lives in a different world (Fig. 1 at left).

1.2 The "indivisible unit", the atom $\left(\alpha \tau \mathrm{o} \mu \varsigma^{1}\right)$ of reality, is equal to one (human) perspective. Our world is made up of a multitude of perceptions, not of a multitude of realities and not of a multitude of atoms (Fig. 1 at right).

1.3 In order to share one's own conception with others, "writing" was invented. Similarly, complex structures, such as landscapes, are "mapped". To map means to write structures.

1.4 Writing helps to become aware. We ask: Is it possible to map = write

1. the distribution of material facts and elements in geometric space? (physics)

2. the distribution of factual events in global time? (history)

3. the distribution of real-world objects across the Earth? (geography)

4. the distribution of elements along material properties? (chemistry)

5. the distribution of growth within surrounding living conditions? 2 ? (biology)

6. the distribution of persons acting in relationships? (sociology)

7. the distribution of individuals between advantage and disadvantage of trade? (economics)

8. the distribution of perspectives within feasible mindsets? (psychology)

9. the distribution of living constructs along selectable senses? (theology)

We see: awareness results from reflection (Fig. 2).

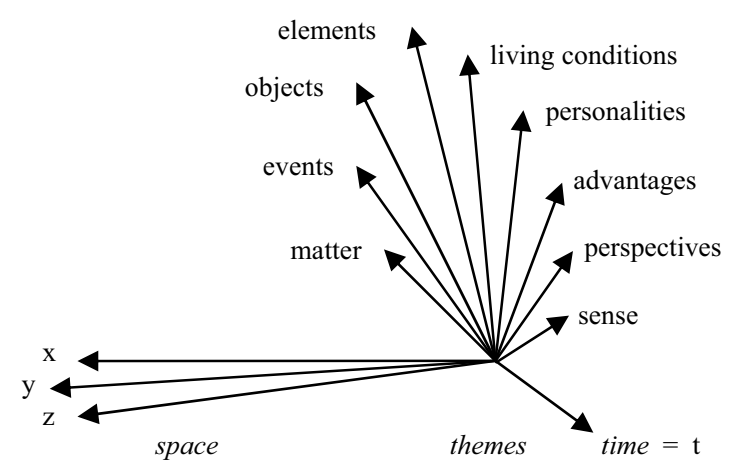

Fig. 2. Fundamental dimensions, along which to coordinate individual world views when reflecting.

\section{Time can be}

1. an attribute of space (a very simple historic GISystem)

2. an independent entity (Einstein's physics)

3. the source of space (cosmology).

In terms of GIS item 2.1 is expressed as " $t$ is one of the components of geo-data" 3 (Fig. 3).

1 what cannot be split any further (Greek)

2 životné prostredie (Slovak): living environment 


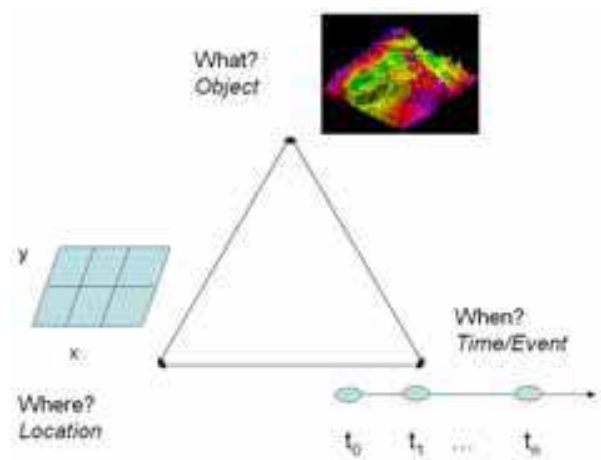

Fig. 3. The where-what-when components of geo-data, also known as triad (Peuquet 2002: 203).

Time can be understood as

- $\quad$ establishing an ordinal scale for events

- driving changes $(=\Delta)$ of realities

- something that unfortunately does not appear on paper.

A proposed solution is to map changing realities $(\Delta)$ instead of mapping time.

Time is replaced by what it produces. This is indicated in Fig. 4.

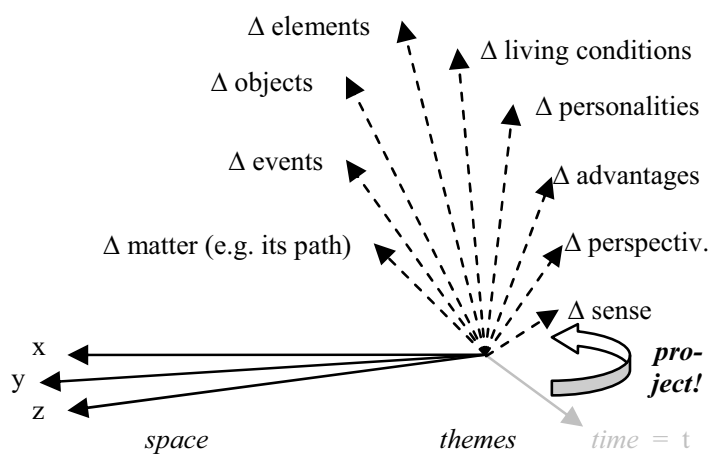

Fig. 4. The projection of time (t) onto the effects of time (the changes $\Delta$ ) can apply to any science.

This idea flips $=$ projects the $\mathrm{t}$ axis onto one of the vertical axes. Time means then: how maps are changed by the envisaged procedures.

Such procedures modify the variables along the axes, be they of physical (gravity force) or of social nature (war).

A classical example is Minard's map of Napoleon's 1812 campaign into Russia ${ }^{4}$ (Fig. 5a, b).

${ }^{3}$ GIScience goes way beyond this view of time and space (considering time as function) because it allows for much more complex queries and analyses.

4 Patriotic War (in Russian): Отечественная война 

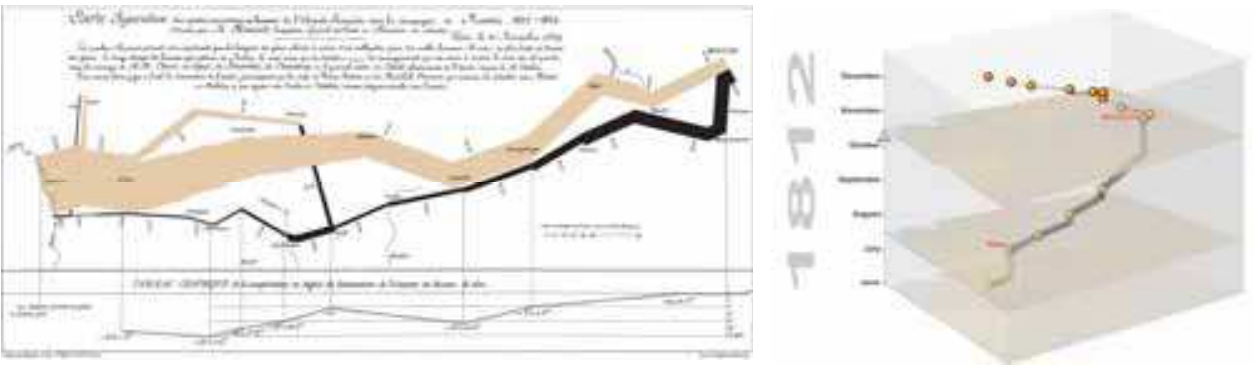

Fig. 5. Notions of path in a geo-space: (a) Minard's map of human losses during Napoleon's 1812 campaign into Russia; and (b) its geovisualisation in a time cube (Kraak, 2009).

Further examples such as landslides in geology, growth of plants, energy economics, economics will be shown in chapter 7 .

For implementing the idea to project the $\mathrm{t}$ axis onto the $\Delta$ axis we need to have clear insight how time quantitatively changes reality.

In other words: we need a model, which (explaining how processes occur) determines the representation of time (Fig. 6). Examples are sliding geology, $\Delta \mathrm{GDP} / \mathrm{cap}$, plant growth.

One cannot perceive time (never!), only its effects: what was perceived in this time span (duration) 5 ? This is why the $t$ axis is projected onto another axis denoting the effect of elapsed time; what this means to the individual sciences is shown in Fig. 4.

Very similarly, in physics nobody can feel force, only its effect (deformation, acceleration), and still forces have been undisputedly a key concept for centuries.

\section{What is time? Just a substrate for procedures. \\ What is space? Just hooks into perceived reality.}

We retain from this chapter 2 that we need a clear model of how elapsing time changes reality. Then we can map time as suggested: by its effects.

\section{How to write time?}

The big picture shows us various examples:

1. as a wheel (see the Indian flag): revolving zodiacs, rounds in stadiums, economic cycles, Kondratieff's waves

2. as an arrow (see Cartesian coordinates): directed processes, causal determinism, $\mathrm{d} / \mathrm{dt}, \mathrm{d}^{2} / \mathrm{dt}^{2}$

3. as the engine for further improvement (evolutionary economics): decrease vs. increase in global income gaps, autopoietic systems, self-organisation

4. as the generator of new structures (institution building, political integration, progressive didactics): new global collaborative institutions, peer-review, culture of understanding, self-responsible learning, interculturality

5. as evolving construct (music).

5 T. de Chardin's (1950) concept of durée (French). 
From this chapter 3 we only keep in mind that the concepts to understand and represent time are fundamentally and culturally different.

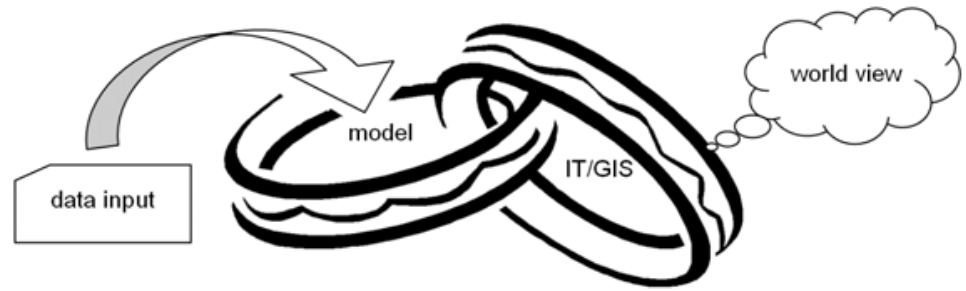

Fig. 6. All data ${ }^{6}$ representations require models.

\section{How to write space?}

The big picture shows us various examples:

1. as a container of any fact and any process (geography and GIS)

2. as result of human action (landscape planning)

3. as evolving construct (architecture).

Examples span space as

- $\quad$ received and prefabricated versus

- final product of one's actions, namely:

1. spaces as the key notion for one's own science: everything that can be georeferenced means GIS

2. space as the product of human activity

3. expanding space into state space: the entirety of possible situations is represented by the space of all "state vectors" which is suitable only if procedures are smooth.

The main thesis here is: the "effects of time" are structurally similar in many scientific disciplines, and they often imply "changes in structures" too. Information Technology (IT) is already providing scientific tools to visualise such structures.

\section{How to map space and time?}

The detailed picture: it is obvious that a choice must be made for one mode of representation and for one view of one scientific discipline:

1. $(x, y ; t)$ : cartography, GIS (Fig. 7)

2. $(x, y, z ; t)$ : geology

3. $\left(x, y, z ; v_{x}, v_{y}, v_{z} ; t\right)$ : landslides

4. $\quad(x, y, z$; biospheric attributes; $t)$ : ecology, tree-line modelling

5. (countries; economic attributes; GDP/cap) or (social attributes; structural shifts; elapsing evolutionary time): economic and social facts in the "Global Change Data Base"7 (Fig. 8)

6. perceiving rhythms and structures: (only) these are "worth recognising": music, architecture, fine arts.

6 datum (Latin): what is given (unquestionable)

7 This GCDB is described in Ahamer (2001) 


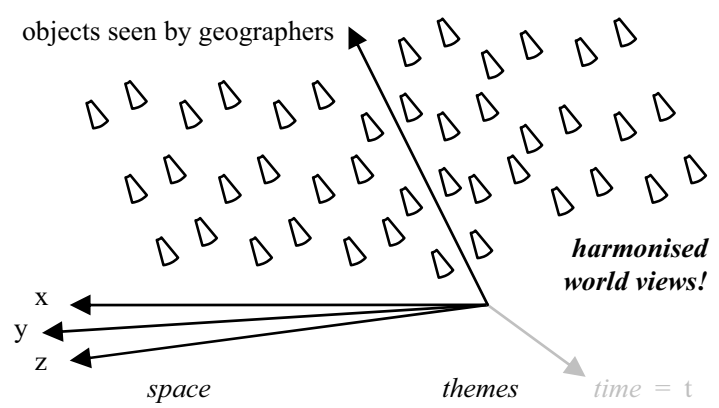

Fig. 7. Harmonising world views: GIS reunites world views by relating everything to its location.

Different sciences may have considerably different outlooks on reality (Fig. 8). A humble attitude of recognising facts 6 instead of believing in the theories one's own discipline offers can empower people to survive even in the midst of other scientific specialties: Galileo's (1632) spirit: give priority to observation, not to theories!

This is the essential advantage of geography as a science: geographers describe realities, just as they appear. Such a model-free concept of science has promoted the usefulness of GIS tools to people independent of personal convictions, scientific models or theories.

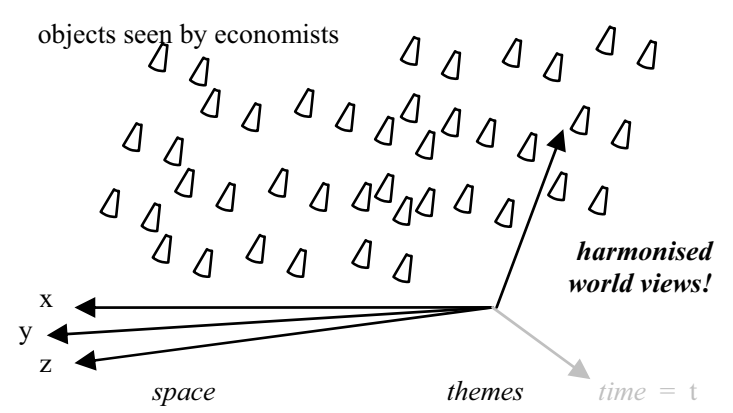

Fig. 8. Different but again internally harmonised world views: explain facts from another angle.

\section{What IT does, did, and could do}

6.1 IT helps to organise the multitude of views (= perceptions) onto data that are generated by humans:

- IT constructs world views, such as: GIS, history, economics, geology, ecology etc.

- IT has already largely contributed to demolishing traditional limitations of space and time:

- Space: tele(-phone, -fax, -vision), virtual globes (Longley et al., 2001)

- Time: e-learning, asynchronous web-based communication, online film storage (Andrienko \& Andrienko 2006). 
6.2 This paper investigates non-classical modes of geo-representation.

We would like to point out that there are two already well-established fields that offer solutions to mapping (space and time, Fig. 9) views: Scientific and information visualisation are branches of computer graphics and user interface design which focus on presenting data to users, by means of interactive or animated digital images. The goal of this field 8 is usually to improve the understanding of the data presented. If the data presented refers to human and physical environments, at geographic scales of measurement, then we talk about Geovisualisation, e.g. (MacEachren, Gahegan et al. 2004; Dykes, MacEachren et al. 2005, Dodge et al., 2008).

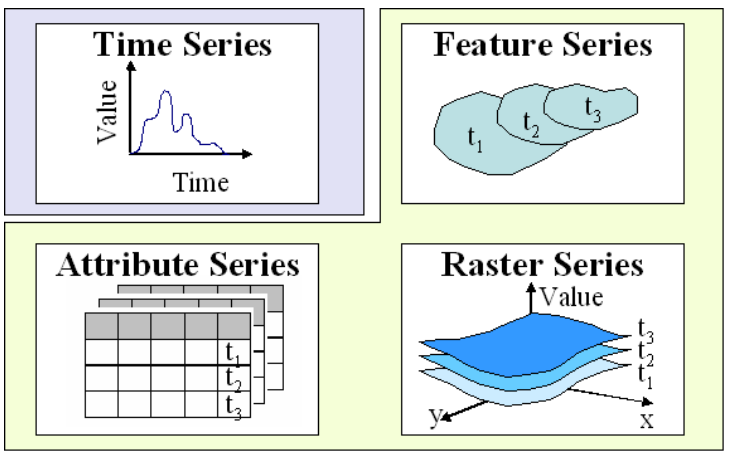

Fig. 9. Time series and three spatio-temporal data types (http://www.crwr.utexas.edu/gis/gishydro05/).

6.3 IT could develop tools that are then interchangeable across scientific disciplines, e.g. landslides that may structurally resemble institutional and economic shifts (see 7.1).

IT could prompt scientists to also look at data structures from other disciplines.

Whatever the disciplines may be, the issues are structures and structural change!

\section{Examples}

The authors are members of the "Time and Space" project at their institution named "Geographic Information Science"9, a part of which explores the cognitive, social, and operational aspects of space \& time in GIScience.

This includes models of both social and physical space and consequences thereof for e.g. spatial analysis and spatial data infrastructures. We investigate how space and time are considered in these application areas, and how well the existing models of space and time meet their specified needs (see e.g. Fig. 9 left). This investigation is expected to identify gaps. Analysis of these gaps will result in improved or new spatio-temporal concepts particularly in support of the above mentioned application areas.

\footnotetext{
8 http://en.wikipedia.org/wiki/Scientific_Visualization

9 The overarching aim of the GIScience Research Unit is to integrate the " $G$ " into Information Sciences (GIScience, 2009)
} 


\subsection{Sliding realities: geology}

The notion of the path in geography $(x, y, t)$ is extended by the $z$ axis (see item 5.2) which produces a map of "time": Fig. 9 left (Zobl, 2009).

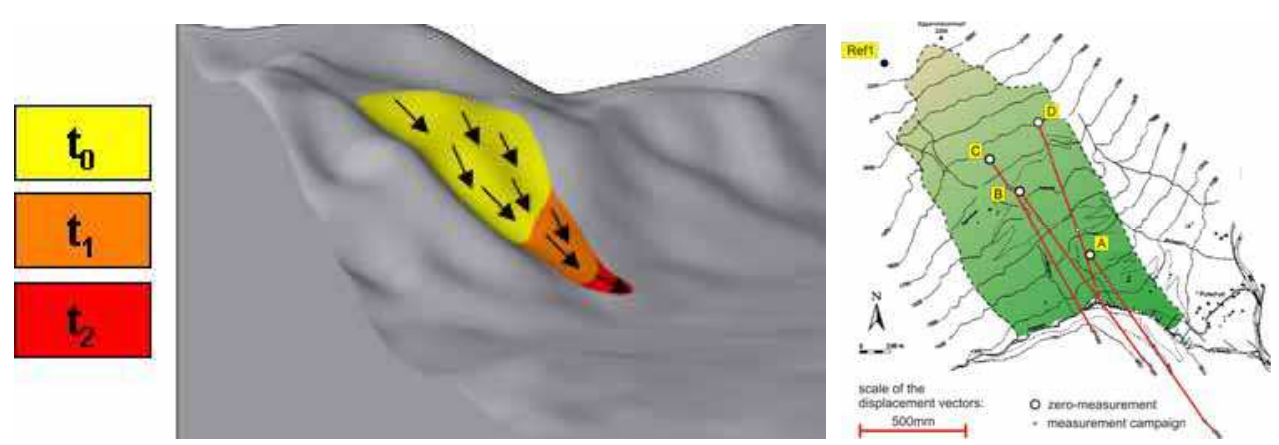

Fig. 9. Left: Geology takes the $(x, y, z ; t)$ world view. Right: These effects of time occur in space, most helpfully. Source: Brunner et al. (2003).

The "effect of time" is sliding (luckily in the same spatial dimensions $x, y, z$ ): we take the red axis in Fig. 9 right. Space itself is sufficiently characteristic for denoting the effects of time.
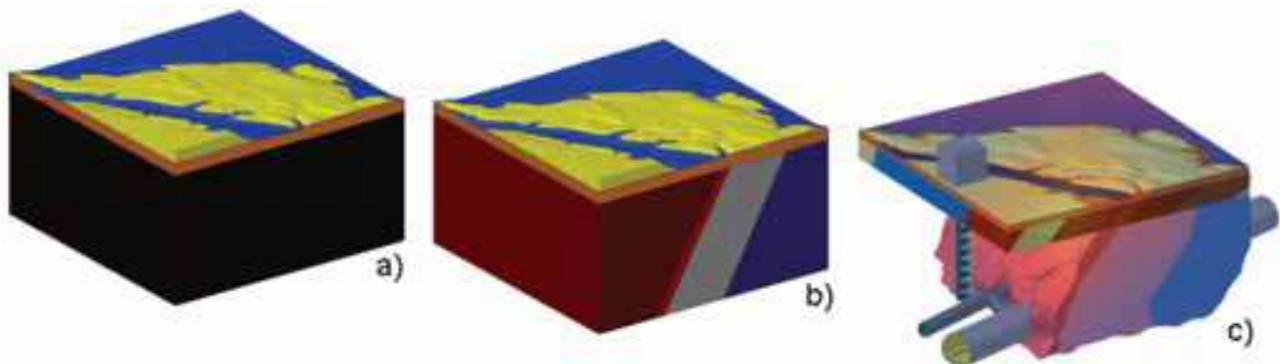

Fig. 10. This series of understandings of bedrock shows how data are stepwise combined with model results in order to reach approximation of understandings (Klima \& Zobl, 2009).

\subsection{Slices of realities: geology}

Despite the lucky coincidence that the effect of time $(\Delta x, \Delta y, \Delta z)$ occurs in the same space $(x$, $\mathrm{y}, \mathrm{z})$ we try to produce slides carrying more information (item 5.3) and hence recur to the socalled attributes mentioned in Fig. 9 such as grey shades or colours.

The speed of sliding $(\mathrm{d} / \mathrm{dt} \mathrm{x}, \mathrm{d} / \mathrm{dt} \mathrm{y}, \mathrm{d} / \mathrm{dt} \mathrm{z})$ is denoted both by horizontal offsets and whitish colours in the spaghettis (Marschallinger, 2009) of Fig. 11. 


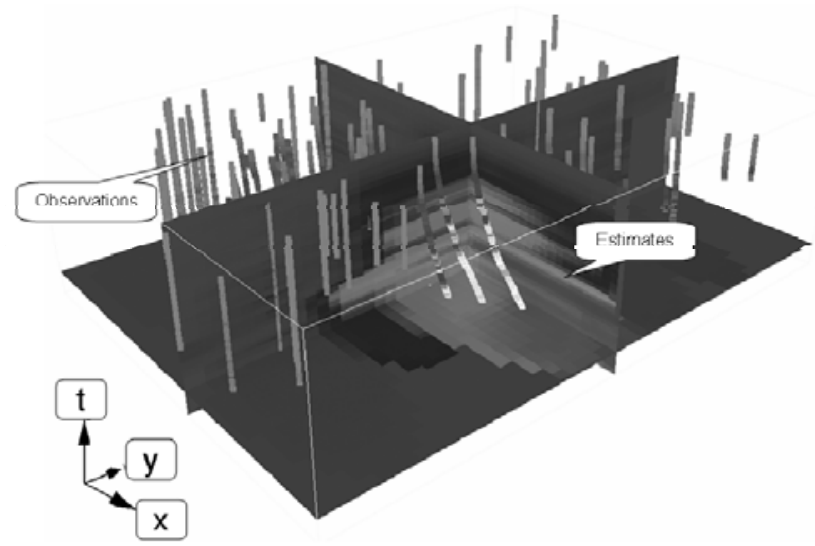

Fig. 11. The $\left(x, y, z ; v_{x}, v_{y}, v_{z} ; t\right)$ view of a landslide process (shades of grey mean speed $\left.v\right)$.

\subsection{Slide shows}

How to map spatial realities that are not any longer isotropic displacement vectors of space itself? For the example of changing tree lines in the Alps (Wallentin, 2009) a slide show is used to present the change of growth patterns made up of the multitude of individual agents $(=$ trees $=$ dots in Fig. 12). Moving spatial structures are depicted as a film of structures (item 5.4).
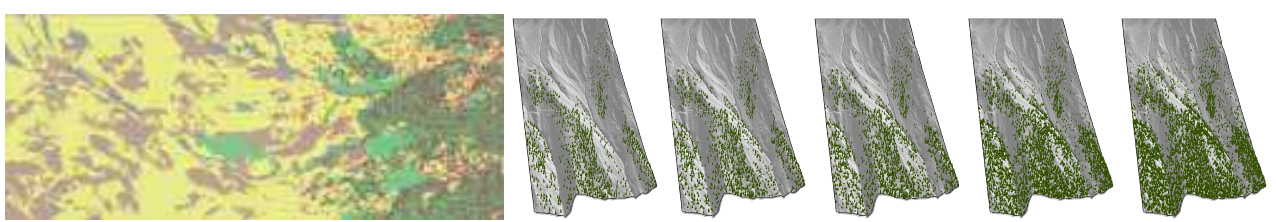

Fig. 12. The $(x, y, z$; biospheric attributes; $t)$ view of the Alpine tree line (above) and its shift induced by climate change as a slide show (below), as computed by the TREELIM model.

In such processes which involve independent behaviour of autonomous agents (here: trees) it becomes seemingly difficult to apply a transformation of space itself, e.g. $d / d t(x, y, z)$.

The model used and its background is briefly described: alpine tree line responses dynamically to changes in the environment. Currently a substantial upwards shift of the alpine tree line can be observed due to land use and climate change. The spatio-temporal tree patterns are modelled in an individual-based approach, where system-level attributes emerge from ecological processes of single trees, their mutual interactions and reactions to environmental factors such as climate or the elevation gradient.

TREELIM is an individual based model that was developed to get a better understanding of the alpine tree line dynamics in respect to land-use change. The model was validated for a case study in Längenfeld, Ötztal (Tyrol, Austria) over a period of 52 years (Wallentin et al. 2008). Individual based models that are structurally realistic model the real-world processes 
that drive landscape patterns (Grimm \& Railsback 2005). Thus TREELIM is designed as a generic model that can be extrapolated in space and time.

Traditionally, individual based models are validated through a model-reality comparison of spatial patterns at a certain point in time. However, a dynamic system does not merely have characteristic spatial patterns, but rather can be described through spatio-temporal patterns. Whereas in non-spatial process models of ecosystems, the temporal aspect is commonly considered as a crucial point in the model validation, this is not the case for spatial models. For spatial models, i.e. models that result in maps as the central model output, the model validation focuses on spatial aspects at a certain point in time (a snapshot situation). Although the temporal aspect may be included to some extent by considering time steps, (i.e. distribution of a spatial feature at several points in time) there is no consideration of spatio-temporal patterns and temporal model uncertainties in the model output variables, as e.g. the average tree line elevation.

\subsection{Global deforestation}

One key driver for global change is deforestation; easy to map as change of land use category of a given area (Fig. 13).
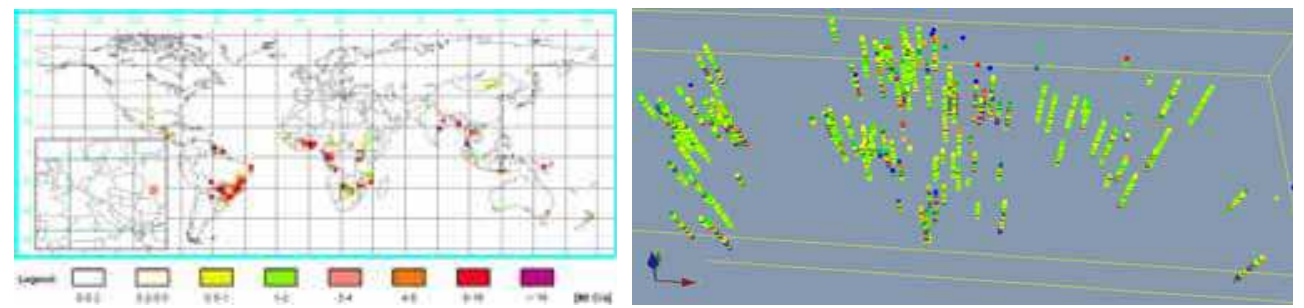

Fig. 13. The $(x, y, z ; \Delta$ biospheric attributes; $t)$ : view of the global deforestation process in megatons carbon. Above: map of carbon flow, below: time series of GCDB data per nation symbolically geo-referenced by the location of their capitals.

This representation is analogous to Fig. 11. In both, the focus shifts from maps $(t) \rightarrow$ maps $(t$, $\Delta t)$. Interest includes temporal dynamics:

$\mathrm{t}=$ colour (above); $\Delta \mathrm{t}=$ height+colour (below), enriching the purely spatial interest.

Even if to the aim is to enlarge the scope of the information delivered from the static map (Fig. 13 above) to the "dynamic map" (Fig. 13 below), readers will remain unsatisfied because no insight into the dynamic properties of deforestation is provided (Fig. 18).

Increasingly, the viewer's focus turns further from "facts" to "changes of facts", to "relationships with driving parameters ${ }^{10 "}$ and to (complex social and political) "patterns ${ }^{11 " .}$

\subsection{Space as text}

Studying geo-referenced data sets (GIS) can help to facilitate bridging interperceptional gaps. Critical GIS literature (e.g. Sarah Elwood) suggests that GIS tools are combined with

10 see the suggested scenarios for water demand, water supply and water quality (Ahamer, 2008)

11 Patterns: name of the journal of the American Society for Cybernetics ASC 
gaining power over space (Fischer, 2008a). Theories going back to Ferdinand de Saussure (Fischer, 2008b) understand space as "text". Societies write space and then read it.

GIS systems are the expression of the ability to "write space", they express the "space views of those being able to write space" (Fischer, 2008c).

\subsection{Spaces constituted by social media}

The concept of Manuel Castell's "space of flows" (Castells, 2004, Ahamer \& Strobl, 2009) sees space as constitutes by communication. Urban planning (Crang, 2000) sees that "electronic media has raised issues of political action, community formation and changing identities". "The metaphorical adoption of urban models is co-determined by electronic sociality and suggests four principle approaches: cities set in or against world flows, suburbanised telecities, communitarian visions and accounts that appeal to a renewed public sphere - all of them shape an electronic architecture. Spatial metaphors and electronic practices are seen as entangled and shaping each other." "In this sense, the 'real' city is the indefinable complexity and folding of spaces-lying outside the visualisations offered of cyberspace."

Urban social relations are co-determined by (electronic) communication (Purcell, 2001; Kirby, 2008).

Users and Non-Users of Social Network Sites exhibit distinct social patterns (Hargittai, 2008) and construct their spaces (and times) in distinct manner (Zheng \& Niu, 2007, Ahamer, 2010).

\subsection{Design of social processes}

Design can be perfomed in and of these following substrates :

- $\quad$ Time $=$ theatre

- $\quad$ Space $=$ architecture

- Geometry = graphics design

- Functionality = design in the narrower sense of industrial design)

- Interests = technology assessment (and administration)

- $\quad$ Structures $=$ arts, science

- $\quad$ Love $=$ new life.

In any of these cases it is necessary to en-act reality in and along time: time is the sequencer for all structures. Finally, en-acting means also the act of love: to "enact" life. Create life. New life.

Design is creative generating of structures. Hence it means the human share in continuous creation. Structures are created in an evolutionary way (Ahamer \& Wahliss, 2008). On the other hand, science is (only) the cognition of structures.

Restrepo \& Christiaans (2004: 3) find after several so-called ethnographic studies where they watch and analyse designers at work that "design is a discursive activity" i.e. a selfreferenced process. "Designers propose design issues, reflect upon and discuss them and for each issue propose answers (also called positions). A discussion about which position to accept (design moves)." "However, problem structuring is not a clearly distinguishable phase of the design process but instead an activity that reoccurs regularly (...) and can contribute to either further structure the problem or to solve it." 
Thomas \& Carroll (1979) discovered that designers tend to treat all problems as though they were ill-defined. They do so by changing the problems constraints and goals - even if the product was well-defined. Designers will be designers even if they can be problem solvers.

Dorst (2004) sees as the main "design problem" that "this process of reasoning is nondeductive". There are "two ways in which a design problem is underdetermined:

1. a description in terms of needs, requirements and intentions can never be complete

2. 'needs, requirements and intentions' and 'structure' belong to different conceptual worlds.

He cites Dorst \& Cross (2001) viewing creativity in the design process as a co-evolution of problem and solution spaces.

As a result, we suggest:

1. Rhythmisation of time (examples: theatre, evolution)

2. Rhythmisation in space and in opinion (examples: court, perspectives, politics, evolution of societal institutions, institution building).

Both these suggested strategies are implemented in the negotiation game "Surfing Global Change" (Ahamer, 2004).

Rhythmisation represents the theatrical strategy and multi-perspectivism represents the geolocating strategy in the "space of perspectives".

\subsection{Space and time for consensus building}

A suitable case study for a heuristic pattern for consensus building evolving in space and time is the five level web based negotiation game (Figure 17), its rules were published as (Ahamer, 2004).

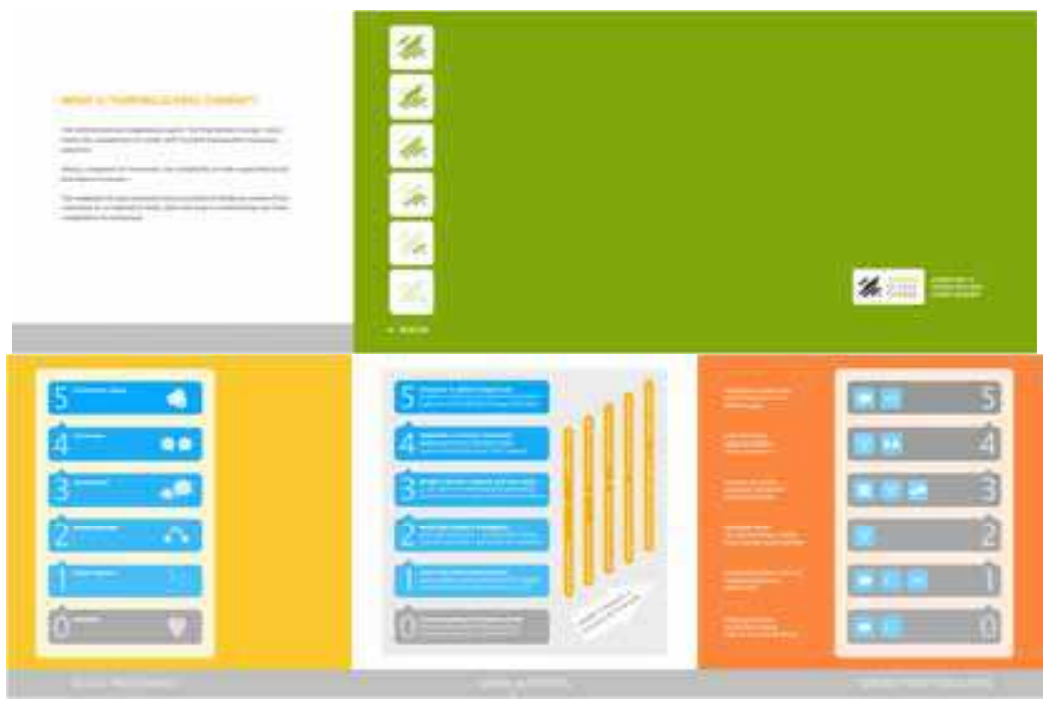

Fig. 17. The "unfolder" gives way to successively deeper levels of detail after embarking on reading (@ G. Ahamer). 


\section{Transformation of coordinates}

8.1 All the above examples have shown that

- various "spaces" can be thought of

- it would be suitable to enlarge the notion of "time".

8.2 Suitably, a transformation of coordinates from time to "functional time" may be thought of.

8.3 In chapter 2, we suggested already to regard time as the substrate for procedures. Consequently, different "times" can be applied to different procedures. As an example, in theoretical physics, the notion of "Eigentime ${ }^{12 "}$ is common and means the system's own time.

8.4 Similar to the fall line in the example of landslides in chapter 7.1 (red in Fig. 10) the direction of the functional time is the highest gradient of the envisaged process. This (any!) time axis is just a mental, cultural construction.

8.5 According to chapter 2 (Fig. 6) a clear understanding (mental model) is necessary to identify the main "effect of time". We see that such an understanding can be culturally most diverse. Just consider the example of economic change:

- optimists think that the global income gap decreases with development

- pessimists believe that it increases, hampering global equity.

8.6 Therefore, any transformation of coordinates bears in itself the imponderability of complex social assumptions about future global development and includes a hypothesis on the global future.

8.7 Still, a very suitable transformation is

$$
\mathrm{t} \rightarrow \mathrm{GDP} / \text { capita }
$$

(Fig. 18) both because of good data availability and increased visibility of paths of development. GDP/cap resembles evolutionary time.

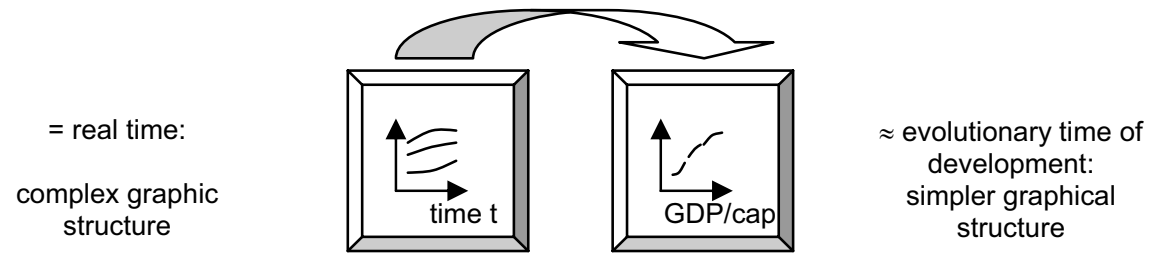

Fig. 18. A suitable transformation of time uses the economic level, measured as GDP per capita.

12 literally (German): the own time (of the system) 
8.8 The strategic interest of such a transformation is "pattern recognition", namely to perceive more easily structures in data of development processes. Examples for such "paths of development" are shown in Fig. 19 for the example of fuel shares in energy economics.

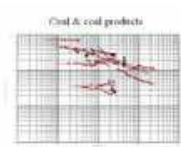

Elomans

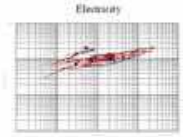

Hawn nat
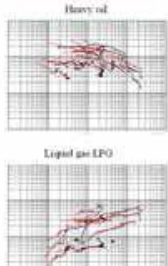

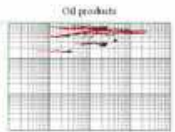

other mitt tunt

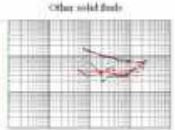

Died

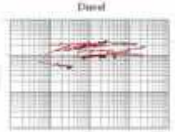

nond

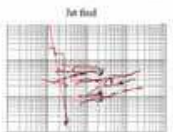

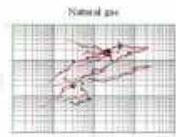

Hes

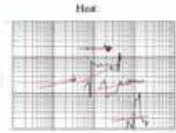

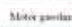
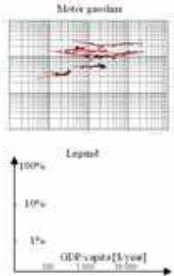

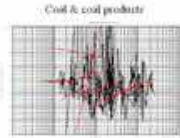

Elationar

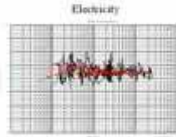

Heny od

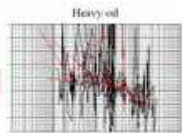

Lipei an vo

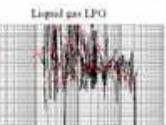

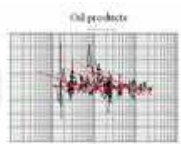

Catho wiliatiad

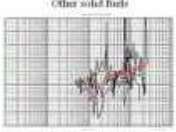

theod

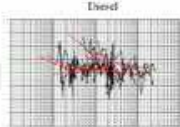

Je sid

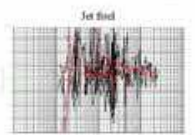

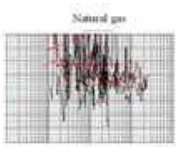

Hest

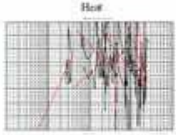

Shat weotent
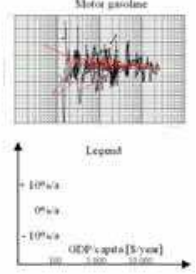

Fig. 19. Structural shift of percentages (left) and change rates of percentages (right) of various fuels in all nations' energy demand 1961-91. Data source: GCDB (Ahamer, 2001).

8.9 It is suggested here that implicitly during many mapping endeavours such transformation occurs. This is legitimate, but care must be taken to take into account the (silently) underlying model of human development.

8.10 Suitable transformation of coordinates can facilitate to see and communicate evolutionary structures, as it enables common views of humans and is therefore helpful for global consensus building.

8.11 Also the "effects of time" are projected into a common system of understanding which might give hope to facilitate common thinking independently of pre-conceived ideologies.

This plan creates the "common reference system of objects".

8.12 This paper suggests enlarging the concept of

to

- "globally universal geo-referencing" (one of the legacies of IT)

- "globally universal view-referencing"

- or "globally universal referencing of perspectives" 13.

Fig. 20 illustrates this step symbolically.

13 The facts themselves may well be delivered by endeavours such as Wikipedia but here it refers to the perspective on facts! A huge voluntarily generated database on people's perceptions, views and opinions would be needed. 


\section{A futuristic vision}

9.1 Building on the vision of "Digital Earth" (Gore, 1998), the deliberations in this paper might eventually lead to the vision of "Digital Awareness": the common perspective on realities valid for the global population, aided by (geo)graphic means.

9.2 The primordial element of (human and societal) evolution is consensus building. Without ongoing creation of consensus global "evolutionary time" is likely to fall back.

\section{The futuristic vision is to map global awareness.}

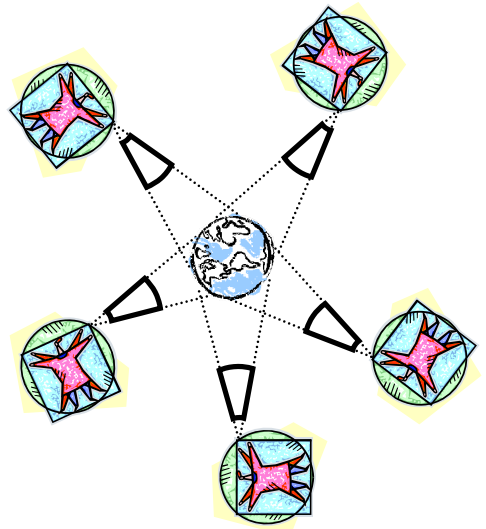

Fig. 20. The global society perceives the world.

9.3 Much like the georeferenced satellites which circulate around the world produce a "Google, Virtual [or similar] Earth", the individual spectators in Fig. 20 circle around the facts - and they create a "common virtual perception": an

\section{IIS = Interperspective Information System.}

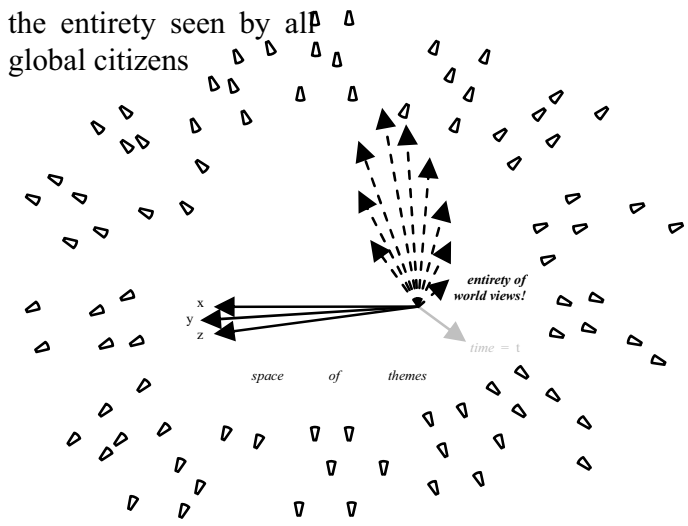

Fig. 21. Divergent perceptions circulate around earthen realities. The entirety of world views creates the IIS (Interperspective Information System). 
9.4 Do we just mean interdisciplinarity? No. Nor do we simply refer to people looking into any direction. Fig. 22 shows the difference to IIS.

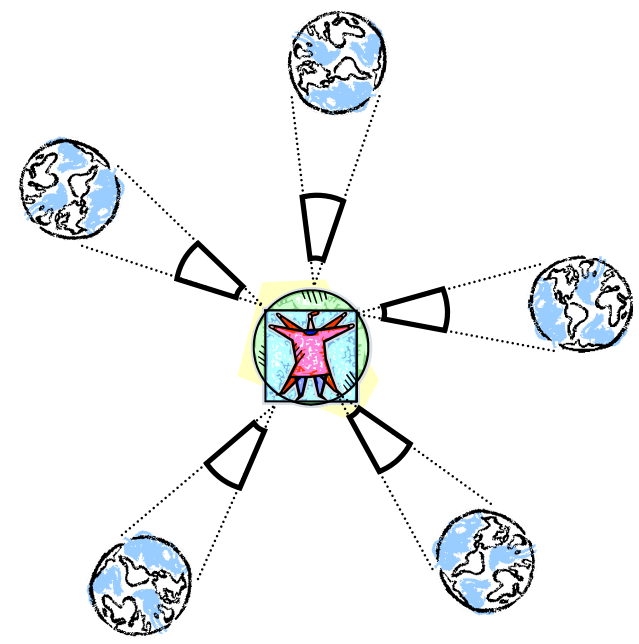

Fig. 22. This is not IIS.

9.5 The science of the third millennium will allow dealing with a multitude of world views and world perspectives (see Tab. 1) with an emphasis on consensus building.

When learning, the emphasis lies on social learning and may also make use of game-based learning (such as the web-based negotiation game "Surfing Global Change") which allows to experimentally experiment with world views without any risk involved.

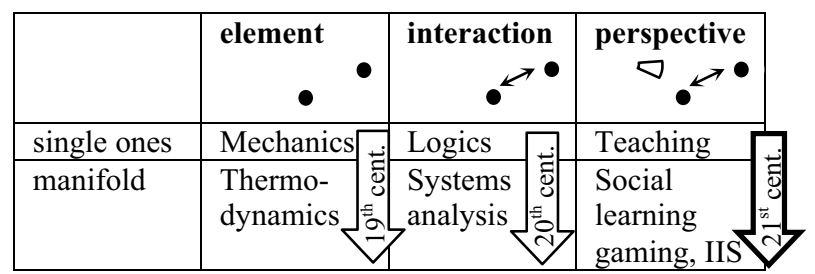

Table 1. The science of the third millennium encompasses multiple perspectives

9.6 A suitable peaceful "common effort 14 " for a peaceful future of humankind would involve developing tools and visual aids in order to understand the opinions of other citizens of the globe.

The future is dialogue.

Or else there will be no future.

جهاد (jihad in Arabic) also means: common effort of a society 


\section{Conclusion}

Sciences are similar to "languages" spoken by people, they differ globally. Understanding for others' languages is essential for global sustainable peace.

Human perceptions are also strongly influenced by underlying models, assumptions and preconceived understandings.

Studying geo-referenced data sets (GIS) can help to facilitate bridging interperceptional gaps.

For the transformation of world views - to make them understandable - it is necessary to know about

- the "effect of time", namely the "path along the continuum of time" which a variable is expected to take

- the speakers' underlying model of a complex techno-socio-economic nature

- the resulting perception of other humans.

A future task and purpose of IT could be to combine the multitude of (e.g. geo-referenced) data and to rearrange it in an easily understandable manner for the viewpoints and perspectives of another scientific discipline or just another human being. Such a system is called Interperspective Information System IIS.

Merging a multitude of perspectives to form a common view of the entire global population is the target of an IIS.

Symbolically, a "Google Earth"-like tool would eventually develop into a "Google World Perspective"-like tool, or a "Virtual Earth"-like tool would become a "Virtual Perspective" tool encompassing all (scientific, social, personal, political, etc.) views in an easily and graphically understandable manner.

In the above futuristic vision, IT can/should(!) become a tool to facilitate consensus finding. It can rearrange the same data for a new view.

Symbolically speaking: similar to Google Earth which allows one to view the same landscape from different angles, a future tool would help to navigate the world concepts, the world views and the world perspectives of the global population.

IT can reorganise extremely large data volumes (if technological growth rates continue) and could eventually share these according to the viewpoint of the viewer.

Such a step of generalisation would lead from "Geographic Information Science" to "Interperspective Information Science", implying the change of angles of perception according to one's own discipline.

Dialogue represents the ultimate heuristics for complex interdisciplinary and intercultural problems. Science does not offer more than such dialogue. 


\section{References}

Ahamer, G. (2001). A Structured Basket of Models for Global Change. In: Environmental Information Systems in Industry and Public Administration (EnvIS). ed. by C. Rautenstrauch and S. Patig, Idea Group Publishing, Hershey, 101-136, http:/ / www.oeaw-giscience.org/ProjectFactSheets/Project

FactSheet_GlobalChange.pdf.

Ahamer, G., Wahliss, W. (2008). Baseline Scenarios for the Water Framework Directive. Ljubljana, WFD Twinning Project in Slovenia, http://www.oeawgiscience.org/ProjectFact Sheets/ProjectFactSheet_EU_SDI.pdf.

Ahamer, G., \& Strobl, J. (2009). Learning across social spaces. In: Cases on Technological Adaptability and Transnational Learning, IGI Publishing, Hershey, USA, pp. 1-24.

Ahamer, G. (2010). Heuristics of social process design, pp. 265-298.

Andrienko, N., Andrienko G. (2006). Exploratory Spatial Analysis, Springer

Brunner, F.K., Zobl, F., Gassner, G. (2003). On the Capability of GPS for Landslide Monitoring. Felsbau 2/2003, 51-54.

Castells, M. (1998). The Information Age: Economy, Society and Culture. Trilogy containing three volumes. Cambridge, MA; Oxford, UK: Blackwell.

Crang, M. (2000). Public Space, Urban Space and Electronic Space: Would the Real City Please Stand Up? Urban Studies, 37(2), 301-317.

de Chardin, T. (1950). La condition humaine [Der Mensch im Kosmos]. Beck, Stuttgart.

Dodge, M., McDerby, M., Turner, M. (eds.) (2008) Geographic Visualisation, Wiley

Dorst, C.H. \& Cross, N.G. (2001). Creativity in the design process: co-evolution of problemsolution, Design Studies, 22, 425-437.

Dorst, K. (2004). On the Problem of Design Problems: problem solving and design expertise. Journal of Design Research, 4(2).

Dykes, J., A. MacEachren, et al. (2005). Exploring Geovisualization. Oxford, Elsevier.

Fischer F. (2008a): Location Based Social Media - Considering the Impact of Sharing Geographic Information on Individual Spatial Experience. In: Car A., Griesebner G. a. J.Strobl (Eds.): Geospatial Crossroads @ GI_Forum '08. Proceedings of the Geoinformatics Forum Salzburg, pp. 90-96.

Fischer F. (2008b): Implications of the usage of mobile collaborative mapping systems for the sense of place. In: M. Schrenk. et al. (Eds.): REAL CORP 008: Mobility Nodes as Innovation Hubs. Proceedings of 13th International Conference on Urban Planning, Regional Development and Information Society, pp. 583-587.

Fischer F. (2008c): Microsoft Virtual Earth. Integrating Geospatial Technology in Everyday Life. Geoinformatics, 4(11), 6-9.

Galileo, G. (1632). Dialogo sopra $i$ due massimi sistemi del mondo, tolemaico, e copernicano. Fiorenza.

GIScience, (2008). Connecting Real and Virtual Worlds. Poster at AGIT'08, http://www.oeaw-giscience.org/index.php?option=com_content\&task=blogcategory \&id $=43 \&$ Itemid $=29$.

Gore, A. (1998). Vision of Digital Earth, http://www.isde5.org/al_gore_speech.htm.

Grimm, V. \& S. F. Railsback, Eds. (2005). Individual-based Modeling and Ecology. Princton Series in Theoretical and Computional Biology. Princton University Press, Princton and Oxford. 
Hargittai, E. (2008). Whose Space: Differences Among Users and Non-Users of Social Network Sites. Journal of Computer-Mediated Communication, 13(1), 276-297.

Kirby, A. (2008). The production of private space and its implications for urban social relations. Political Geography, 27(1), 74-95

Klima, K. \& Zobl F. (2009, in press). Herausforderung der geologischen Erkundung und der Untergrundmodellierung für die geotechnische Analyse Herausforderung der geologischen Erkundung und der Untergrundmodellierung für die geotechnische Analyse. Key note paper published in: Tagungsband Computerorientierte Geologie 2009 in Salzburg, Wichmann.

Kraak (2009). Minard's map. www.itc.nl/personal/kraak/1812/3dnap.swf

Longley, P.A. et al. (2001) Geographic Information. Science and Systems. Wiley

MacEachren, A. M., M. Gahegan, et al. (2004). Geovisualization for Knowledge Construction and Decision Support. IEEE Computer Graphics \& Applications 2004 (1/2): 13-17.

Marschallinger, R. (2009). Analysis and Integration of Geo-Data. http://www.oeawgiscience.org/.

Peuquet, D. J. (2002). Representations of Space and Time. New York, The Guilford Press.

Restrepo, J., Christiaans, H. (2004). Problem Structuring and Information Access in Design. Journal of Design Research, 4(2).

Thomas, J. \& Carroll, J. (1979). The psychological study of design. Design Studies, 1(1), 5-11.

Wallentin, G., U. Tappeiner, J. Strobl \& E. Tasser (2008). Alpine tree line dynamics: an individual based model. Ecological Modelling, 218(3-4). p. 235-246, doi:10.1016/j.ecolmodel.2008.07.005.

Wallentin, G. (2009). Ecology \& GIS. Spatiotemporal modelling of reforestation processes. See http://www.oeaw-giscience.org/images/stories/Downloads/pecha\%20kucha $\% 20$ technoz\% 20day.pdf

Zheng., J. \& Niu, J. (2007). Unified Mapping of Social Networks into 3D Space. IMSCCS 2007, Second International Multi-Symposiums on Computer and Computational Sciences. See http://ieeexplore.ieee.org/xpl/conferences.jsp.

Zobl, F. (2009). Mapping, Modelling and Visualisation of georelevant processes. http://www.oeaw-giscience.org/. 
Compulational Intelligence

-

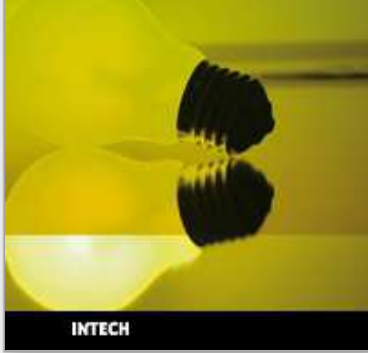

\section{Computational Intelligence and Modern Heuristics}

Edited by Al-Dahoud Ali

ISBN 978-953-7619-28-2

Hard cover, 348 pages

Publisher InTech

Published online 01, February, 2010

Published in print edition February, 2010

The chapters of this book are collected mainly from the best selected papers that have been published in the 4th International conference on Information Technology ICIT 2009, that has been held in Al-Zaytoonah University, Jordan in the period 3-5/6/2009. The other chapters have been collected as related works to the topics of the book.

\section{How to reference}

In order to correctly reference this scholarly work, feel free to copy and paste the following:

Gilbert Ahamer, Adrijana Car, Robert Marschallinger, Gudrun Wallentin and Fritz Zobl (2010). Heuristics and Pattern Recognition in Complex Geo-Referenced Systems, Computational Intelligence and Modern Heuristics, Al-Dahoud Ali (Ed.), ISBN: 978-953-7619-28-2, InTech, Available from:

http://www.intechopen.com/books/computational-intelligence-and-modern-heuristics/heuristics-and-patternrecognition-in-complex-geo-referenced-systems

\section{INTECH}

open science / open minds

\section{InTech Europe}

University Campus STeP Ri

Slavka Krautzeka 83/A

51000 Rijeka, Croatia

Phone: +385 (51) 770447

Fax: +385 (51) 686166

www.intechopen.com

\section{InTech China}

Unit 405, Office Block, Hotel Equatorial Shanghai

No.65, Yan An Road (West), Shanghai, 200040, China

中国上海市延安西路65号上海国际贵都大饭店办公楼405单元

Phone: +86-21-62489820

Fax: +86-21-62489821 
(C) 2010 The Author(s). Licensee IntechOpen. This chapter is distributed under the terms of the Creative Commons Attribution-NonCommercial-ShareAlike-3.0 License, which permits use, distribution and reproduction for non-commercial purposes, provided the original is properly cited and derivative works building on this content are distributed under the same license. 